\title{
Late deaths after treatment for childhood cancer
}

\author{
M M Hawkins, J E Kingston, L M Kinnier Wilson
}

\begin{abstract}
An investigation of 749 deaths occurring among $\mathbf{4 0 8 2}$ patients surviving at least five years after the diagnosis of childhood cancer in Britain before 1971 has been undertaken. Of the 738 with sufficient information the numbers of deaths attributable to the following causes were: recurrent tumour, 550 (74\%), a second primary tumour, $61(8 \%)$, a medical condition related to treatment of the tumour, $49(7 \%)$, an traumatic death unrelated to the tumour or its treatment, $34(5 \%)$, finally, any other cause unrelated to the tumour or its treatment, 44 (6\%).
\end{abstract}

Less than $10 \%$ of five year survivors of non-Hodgkin lymphomas, neuroblastoma, retinoblastoma, Wilms' tumour, or a soft tissue sarcoma died of recurrent tumour during the next 15 years, while more than $25 \%$ of five year survivors of Hodgkin's disease, ependymoma, medulloblastoma, and Ewing's tumour died of recurrent tumour during the corresponding period. Almost $50 \%$ of five year survivors of acute lymphoblastic leukaemia died of recurrent disease during the corresponding 15 years, a large proportion of deaths being due to central nervous system relapse in an era before central nervous system prophylaxis was routinely given.

Comparison of the mortality observed with that expected from mortality rates in the general population indicated three times the expected number of deaths from nonneoplastic causes. Five times the expected number of deaths from cardiovascular causes were observed, these were predominantly myocardial infarction and cerebrovascular accidents. There was no evidence of an excess in the number of suicides observed, but there were three times the expected number of deaths from accidents observed after central nervous system tumours.

Two groups of patients were identified whose deaths were potentially avoidable. Seven patients with craniopharyngioma and panhypopituitarism presented with addisonian crises during periods of stress not adequately covered by exogenous corticosteroids. In the other group were children who received radiotherapy and later developed problems related to radiation fibrosis.

We emphasise that our investigation relates to patients diagnosed with childhood cancer before 1971. The pattern of mortality that will emerge after recent treatment regimens, in which chemotherapy is being used more extensively, is likely to be different from that observed in our study.
Examination of the course of events leading to death among patients who survive at least five years after childhood cancer is important as it may provide further understanding of late relapse and the late effects of treatment. With the benefit of hindsight it may be possible to identify deaths that might have been preventable. If the study population is large it is likely that deaths from rare adverse consequences of the neoplastic disease or its treatment will be identified. Such an investigation requires clinical information relating to the circumstances of death and therefore access to sources other than the death certificates, including hospital records and reports from postmortem examination.

A comparison of the mortality observed with that expected from mortality in the general population, for specific causes of death-both neoplastic and non-neoplastic-may also provide further insight into the curability of childhood neoplastic disease and identify any departure from the expected pattern of mortality. For this type of comparison it is necessary to rely on death certification because the expected numbers are derived from general population rates which are themselves based on death certificates alone.

This paper is complementary to our previous report on long term survival and cure after childhood cancer. ${ }^{1}$

\section{Methods}

The national register for childhood tumours, maintained by the Childhood Cancer Research Group in Oxford, has been routinely notified of tumours occurring in children under 15 years of age since 1962 through the national cancer registration scheme operating in Great Britain. This provides, within the limits of completeness of registration, a population based series of childhood cancer cases. From among these we have selected 2537 cases diagnosed before 1971 who survived for at least five years. A further 1545 cases, diagnosed between 1940 and 1961 inclusive, surviving at least five years, and treated at centres where complete lists of patients were available, have also been included.

A consequence of restricting the study to this period of diagnosis is that we are primarily concerned with malignant disease that was amenable to treatment with radiation and surgery, as apart from the treatment of leukaemia, cytotoxics were not in widespread use before 1971 . An advantage of studying this period, however, is that sufficient time has elapsed to examine late mortality.
Correspondence to: Dr Hawkins.

Accepted 13 June 1990 
For deaths occurring five or more years from diagnosis, an effort was made to obtain medical details of the circumstances leading to death. A complete copy of all relevant hospital notes extant was obtained together with a copy of the report when a postmortem examination had been undertaken.

The underlying cause of death, based on all the information available, was coded according to the following broad categories: (1) recurrent tumour; (2) a medical condition related to treatment of the tumour; (3) a second primary tumour; (4) a traumatic death apparently unrelated to the tumour or its treatment; (5) any other cause apparently unrelated to the tumour or its treatment; and (6) insufficient information.

A few conventions were used in coding deaths into these broad categories. In patients with tumours of the central nervous system, the cause of death given on the death certificate was frequently bronchopneumonia. Examination of the case records of a number of these patients showed that their general health had gradually declined, the patients had become obtunded due to recurrent tumour and had eventually died from bronchopneumonia. These deaths were all coded as recurrent tumour rather than infection. When death occurred from infections such as herpes zoster, meningitis, or pneumonia in patients on chemotherapy then they were coded as a death from a medical condition related to treatment of the tumour. One patient with Hodgkin's disease who had undergone a splenectomy and had subsequently died from a pneumococcal septicaemia, while in remission, was also coded to a medical condition related to treatment. When death occurred from infection or other cause and where there was insufficient evidence to determine whether the patient had active disease at the time, then the death was coded to insufficient information.

For the purposes of comparing the mortality observed with that expected we also recorded the International Classification of Diseases (ICD) code appearing on the death certificate. We restricted the study to revisions $6,7,8$, and 9 of ICD, ${ }^{2-5}$ and therefore only deaths occurring after 1949 are included in this comparison. This excluded one death.

Survival was examined using standard techniques. ${ }^{6}$ Mortality from specific causes of death among survivors was compared with that expected from the general population of England and Wales (Office of Population Censuses and Surveys, unpublished report). Observed and expected numbers of deaths were compared using exact Poisson methods.

\section{Results}

Of the 4082 five year survivors eligible for analysis, there were 749 deaths. A death certificate was obtained for 739 of these deaths, hospital notes for 359, and a postmortem examination report for 76 .

Table 1 gives the causes of late death occurring among patients surviving for at least five years after diagnosis of various childhood neoplasms. There was insufficient information available to code the cause of death in 11 patients. Approximately $74 \%$ of the deaths were attributed to recurrent tumour, and $8 \%$ to the occurrence of a second primary tumour. There was substantial variability in the relative proportions of deaths from different causes depending on the primary diagnosis: over $75 \%$ of deaths after acute lymphoblastic leukaemia, lymphoma, and tumours of the central nervous system or bone were due to recurrent tumour. In contrast, only $26 \%$ of deaths among patients surviving at least five years after genetic retinoblastoma were due to recurrent tumour, with $65 \%$ resulting from second primary tumours. Similarly, among patients surviving at least five years after Wilms' tumour only $36 \%$ of deaths were due to recurrent tumour with $32 \%$ resulting from second primary tumours.

Table 2 gives the variation in causes of death with follow up. Among deaths occurring five to nine years from diagnosis recurrent tumour was the most common cause of death after each childhood neoplasm. The most common cause of death among 10 year survivors varied considerably depending on the neoplasm: in patients with acute lymphoblastic leukaemia, Hodgkin's disease, and central nervous system tumours, recurrent tumour was still the most common cause, whereas in patients with retinoblastoma and Wilms' tumour, death from second primary tumours predominated.

There were 188 deaths from causes other than recurrent tumour (table 1). Of these, we obtained hospital notes and/or a postmortem

Table 1 Frequency (\%) of different causes of death observed among those surviving five or more years from diagnosis

\begin{tabular}{|c|c|c|c|c|c|c|c|c|c|c|c|}
\hline & $\begin{array}{l}\text { Acute } \\
\text { bymphoblastic } \\
\text { leukaemia }\end{array}$ & Lymphomas & $\begin{array}{l}\text { Tumour } \\
\text { of central } \\
\text { neroous system }\end{array}$ & Neuroblastoma & $\begin{array}{l}\text { Genetic } \\
\text { retinoblastoma }\end{array}$ & $\begin{array}{l}\text { Non-genetic } \\
\text { retinoblastoma }\end{array}$ & $\begin{array}{l}\text { Wilms' } \\
\text { tumour }\end{array}$ & $\begin{array}{l}\text { Malignant } \\
\text { bone }\end{array}$ & $\begin{array}{l}\text { Soft } \\
\text { tissue }\end{array}$ & $\begin{array}{l}\text { Other } \\
\text { neoplasms }\end{array}$ & $\begin{array}{l}\text { All } \\
\text { neoplasms }\end{array}$ \\
\hline $\begin{array}{l}\text { Recurrent tumour } \\
\text { Medical condition }\end{array}$ & $78(95)^{*}$ & $97(79)$ & $260(79)$ & $15(63)$ & $8(26)$ & & $8(36)$ & $23(79)$ & $24(67)$ & $37(65)$ & $550(74)$ \\
\hline $\begin{array}{l}\text { (related to treatment) } \\
\text { Second primary tumour } \\
\text { Accident, suicide, or }\end{array}$ & $2(2)$ & $\begin{aligned} 10(8) \\
2(2)\end{aligned}$ & $\begin{array}{l}28(8) \\
12(4)\end{array}$ & $\begin{array}{l}4(16) \\
2(8)\end{array}$ & $20(65)$ & $3(60)$ & $\begin{array}{l}2 \text { (9) } \\
7 \text { (32) }\end{array}$ & $\begin{array}{ll}1 & (3) \\
3 & (10)\end{array}$ & $\begin{array}{l}1 \text { (3) } \\
4 \text { (11) }\end{array}$ & $\begin{array}{ll}1 & (2) \\
8 & (14)\end{array}$ & $\begin{array}{l}49(7) \\
61(8)\end{array}$ \\
\hline $\begin{array}{l}\text { homicide } \\
\text { Other cause (unrelated } \\
\text { to tumour or its }\end{array}$ & & $6(5)$ & $17(5)$ & $1(4)$ & $1(3)$ & $1(20)$ & $2(9)$ & $1(3)$ & $1(3)$ & $4(7)$ & $34(5)$ \\
\hline $\begin{array}{l}\text { treatment) } \\
\text { Unsufficient information }\end{array}$ & $2^{2(2)}$ & $\begin{array}{l}8(6) \\
1\end{array}$ & $12(4)$ & $2(8)$ & $2(6)$ & $1(20)$ & $3(14)$ & $1(3)$ & $\begin{array}{l}6(17) \\
2\end{array}$ & $7(12)$ & $\begin{array}{l}44(6) \\
11\end{array}$ \\
\hline Total deaths & 84 & 124 & 334 & 24 & 31 & 5 & 22 & 30 & 38 & 57 & 749 \\
\hline $\begin{array}{l}\text { Total No of } 5 \text { year } \\
\text { survivors }\end{array}$ & 171 & 538 & 1257 & 230 & 267 & 287 & 365 & 151 & 352 & 464 & 4082 \\
\hline
\end{tabular}


Table 2 Frequency of different causes of death observed at varying times from diagnosis

\begin{tabular}{|c|c|c|c|c|c|c|c|c|c|c|c|c|}
\hline & \multirow[t]{2}{*}{$\begin{array}{l}\text { No of } \\
5 \text { year } \\
\text { survivors }\end{array}$} & \multicolumn{5}{|c|}{$\begin{array}{l}\text { Causes of death } \\
5-9 \text { years from } \\
\text { diagnosis }\end{array}$} & \multirow[t]{2}{*}{$\begin{array}{l}\text { No of } \\
10 \text { year } \\
\text { survivors }\end{array}$} & \multicolumn{5}{|c|}{$\begin{array}{l}\text { Causes of death } \\
10-14 \text { years from } \\
\text { diagnosis }\end{array}$} \\
\hline & & $\begin{array}{l}\text { Recurrent } \\
\text { tumour }\end{array}$ & $\begin{array}{l}\text { Related } \\
\text { medical } \\
\text { condition* }\end{array}$ & $\begin{array}{l}\text { Second } \\
\text { primary } \\
\text { tumour }\end{array}$ & Accident & $\begin{array}{l}\text { Other } \\
\text { causef }\end{array}$ & & $\begin{array}{l}\text { Recurrent } \\
\text { tumour }\end{array}$ & $\begin{array}{l}\text { Related } \\
\text { medical } \\
\text { condition }^{*}\end{array}$ & $\begin{array}{l}\text { Second } \\
\text { primary } \\
\text { tumour }\end{array}$ & Accident & $\begin{array}{l}\text { Other } \\
\text { causef }\end{array}$ \\
\hline \multicolumn{13}{|l|}{ Acute lymphoblastic } \\
\hline Hodgkin's disease & 328 & 70 & 4 & 1 & 3 & & 247 & 9 & 4 & & & 1 \\
\hline Non-Hodgkin lymphoma & 203 & 12 & 1 & & 2 & 2 & 181 & & & & & 1 \\
\hline nervous system & 1257 & 163 & 12 & 2 & 5 & 1 & 1066 & 56 & 4 & 2 & 7 & 4 \\
\hline Neuroblastoma & 230 & 11 & & & & & 219 & 2 & 1 & & & 2 \\
\hline Genetic retinoblastoma & 267 & 6 & & 3 & 1 & 1 & 256 & 1 & & 8 & & \\
\hline Non-genetic retinoblastoma & 287 & & & & & & 283 & & & 1 & & \\
\hline Wilms' tumour & 365 & 7 & 1 & & & & 354 & & & $i$ & & \\
\hline Osteosarcoma & 73 & 6 & 1 & 1 & & & 65 & & & & & \\
\hline Ewing's sarcoma & 40 & 10 & & & & & 30 & 1 & & & & \\
\hline Soft tissue sarcomas & 352 & 18 & 1 & 1 & & 1 & 326 & 5 & & 2 & & 1 \\
\hline Other neoplasms & 509 & 35 & & 3 & & 2 & 467 & 4 & 1 & 2 & 1 & 1 \\
\hline All neoplasms & 4082 & 408 & 22 & 11 & 11 & 9 & 3589 & 84 & 10 & 16 & 8 & 10 \\
\hline
\end{tabular}

The number of patients who survive to a specified time does not equal the number surviving in the previous time interval plus deaths in the interim *Medical condition related to treatment of the tumour.

Traumatic death unrelated to tumour or its treatment-that is, accident, suicide, or homicide.

$\ddagger$ Any other cause unrelated to tumour or its treatment.

Table 3 Deaths not directly related to tumour or its treatment $(n=44)$

\begin{tabular}{|c|c|c|c|}
\hline Original diagnosis & Cause of death & Associated condition & $\begin{array}{l}\text { Interval from } \\
\text { diagnosis to } \\
\text { death (years) }\end{array}$ \\
\hline Hodgkin's disease & Coronary atherosclerosis & & 21 \\
\hline Hodgkin's disease & Coronary atherosclerosis & & 20 \\
\hline Non-Hodgkin lymphoma & Coronary atherosclerosis & Diabetes mellitus & 11 \\
\hline Osteosarcoma & Coronary atherosclerosis & Addison's disease, diabetes mellitus & 18 \\
\hline Fibrosarcoma & Coronary atherosclerosis & & 30 \\
\hline Fibrosarcoma & Coronary atherosclerosis & & 23 \\
\hline Melanoma of eye & Coronary atherosclerosis & & 23 \\
\hline Thymoma & Coronary atherosclerosis & Aortic valve incompetence & 13 \\
\hline Ependymoma & Congenital heart disease & & 5 \\
\hline Astrocytoma & Congestive cardiac failure & Severe kyphoscoliosis & 13 \\
\hline Non-Hodgkin lymphoma & Cerebrovascular accident & Chronic renal failure & 35 \\
\hline Astrocytoma & Cerebrovascular accident & Disseminated lupus erythematosus & 12 \\
\hline Astrocytoma & Cerebrovascular accident & & 20 \\
\hline Cancer of thyroid & Cerebrovascular accident & Malignant hypertension & 16 \\
\hline Epithelioma & Cerebrovascular accident & & 28 \\
\hline Neuroblastoma & Cerebrovascular accident & & 12 \\
\hline Dysgerminoma & Cerebrovascular accident & Malignant hypertension & 16 \\
\hline Astrocytoma & $\begin{array}{l}\text { Pulmonary embolus/deep venous } \\
\text { thrombosis }\end{array}$ & Postpartum & 15 \\
\hline Astrocytoma & $\begin{array}{l}\text { Pulmonary embolus/deep venous } \\
\text { thrombosis }\end{array}$ & Tegretol hepatitis & 23 \\
\hline Medulloblastoma & Cor pulmonale/bronchiectasis & Hypogammaglobulinaemia & 22 \\
\hline Retinoblastoma & Pneumonia & Mental retardation & 7 \\
\hline Astrocytoma & Pneumonia & & 13 \\
\hline Acute lymphoblastic leukaemia & Chicken pox pneumonia & & 5 \\
\hline Tumour of central nervous system & Aspiration pneumonia & After oesophageal dilatation & 28 \\
\hline Rhabdomyosarcoma & Apiration pneumonia & After fit & 21 \\
\hline Optic nerve glioma & Meningitis & & 12 \\
\hline Wilms' tumour & Encephalitis & & 19 \\
\hline Dysgerminoma & Streptococcal septicaemia & Diabetes mellitus & 7 \\
\hline Retinoblastoma & Acute renal failure & & 55 \\
\hline Fibrosarcoma & Acute renal failure & & 6 \\
\hline Non-Hodgkin lymphoma & Chronic renal failure & & 7 \\
\hline Wilms' tumour & Chronic renal failure & & 23 \\
\hline Neuroblastoma & Chronic renal failure & Spina bifida & 11 \\
\hline Retinoblastoma & Diabetic ketoacidosis & & 15 \\
\hline Optic nerve glioma & Hypoglycaemic coma & Diabetes mellitus & 16 \\
\hline Hodgkin's disease & Cirrhosis & Collagenosis & 16 \\
\hline Non-Hodgkin lymphoma & Acute hepatitis & & 6 \\
\hline Astrocytoma & After cholecystectomy & & 38 \\
\hline Wilms' tumour & After mitral valve replacement & & 30 \\
\hline Langerhans cell histiocytosis & After aortic valve replacement & & 7 \\
\hline Hodgkin's disease & Gastric ulcer & & 13 \\
\hline Fibrosarcoma & Intestinal obstruction & & 14 \\
\hline Fibrosarcoma & Motor neurone disease & & 44 \\
\hline Acute lymphoblastic leukaemia & Cerebral degeneration & & 9 \\
\hline
\end{tabular}

examination report for $150(80 \%)$. A postmortem examination report was obtained for $\mathbf{4 0}$ $(21 \%)$ of these deaths.

Of the deaths occurring from causes other than recurrent disease, $44(6 \%)$ were due to causes not directly related to the tumour or its treatment (table 3). However, $49(7 \%)$ of the deaths in five year survivors occurred from medical conditions related to treatment (table
4). The major causes of death in this group included infection $(n=16)$, problems related to radiotherapy $(n=13)$, and adrenal failure $(n=7)$.

Traumatic deaths due to accidents, suicide, or homicide accounted for $5 \%$ of the deaths in five year survivors.

Table 5 gives the proportion of five year survivors subsequently dying of recurrent tumour within the next 15 years. Deaths from causes 


\begin{tabular}{|c|c|c|c|c|c|c|c|c|c|c|}
\hline \multirow[t]{2}{*}{$\begin{array}{l}\text { No of } \\
15 \text { year } \\
\text { survivors }\end{array}$} & \multicolumn{4}{|c|}{$\begin{array}{l}\text { Causes of death } \\
15-19 \text { years from } \\
\text { diagnosis }\end{array}$} & \multirow[t]{2}{*}{$\begin{array}{l}\text { No of } \\
20 \text { year } \\
\text { survivors }\end{array}$} & \multicolumn{5}{|c|}{$\begin{array}{l}\text { Causes of death } \\
20+\text { years from } \\
\text { diagnosis }\end{array}$} \\
\hline & $\begin{array}{l}\text { Recurrent } \\
\text { tumour }\end{array}$ & $\begin{array}{l}\text { Related } \\
\text { medical } \\
\text { condition" }\end{array}$ & $\begin{array}{l}\text { Second } \\
\text { primary } \\
\text { tumour }\end{array}$ & $\begin{array}{r}\text { Accident Other } \\
\text { cause }\end{array}$ & & $\begin{array}{l}\text { Recurrent } \\
\text { tumour }\end{array}$ & $\begin{array}{l}\text { Related } \\
\text { medical } \\
\text { condition* }\end{array}$ & $\begin{array}{l}\text { Second } \\
\text { primary } \\
\text { tumour }\end{array}$ & Accident & $\begin{array}{l}\text { Other } \\
\text { causef }\end{array}$ \\
\hline
\end{tabular}

\begin{tabular}{|c|c|c|c|c|c|c|c|c|c|c|c|}
\hline 87 & 1 & & & & & 22 & 1 & & & & \\
\hline 231 & 3 & 1 & & & 1 & 133 & 2 & & 1 & 1 & 2 \\
\hline 180 & 1 & & & & & 121 & & & & & 1 \\
\hline 986 & 26 & 4 & 4 & 3 & 2 & 658 & 15 & 8 & 4 & 2 & 5 \\
\hline 214 & 2 & 2 & & & & 151 & & 1 & 2 & 1 & \\
\hline 247 & 1 & & 5 & & & 189 & & & 4 & & 1 \\
\hline 282 & & & & 1 & 1 & 191 & & & 2 & & \\
\hline 352 & & 1 & 3 & 1 & 1 & 220 & 1 & & 3 & 1 & 2 \\
\hline 65 & 1 & & & & 1 & 46 & & & 2 & & \\
\hline 29 & 1 & & & & & 19 & & & & & \\
\hline 314 & 1 & & & & & 240 & & & 1 & 1 & 4 \\
\hline 456 & 1 & & 1 & 2 & 2 & 316 & 1 & & 2 & 2 & 2 \\
\hline 3443 & 38 & 8 & 13 & 7 & 8 & 2306 & 20 & 9 & 21 & 8 & 17 \\
\hline
\end{tabular}

because of losses to follow up. blastic leukaemia died from recurrent disease during a similar period. Late relapse and death were also common in Hodgkin's disease, ependymoma, medulloblastoma, and Ewing's tumour with more than a quarter of the five year survivors dying of recurrent tumour within the subsequent 15 years.

Table 6, derived from death certificate coding, gives a comparison of the observed and expected number of deaths from particular neoplasms for which it is possible to define a range of ICD codes, which is almost certain to include any death from recurrent tumour. A measure of the excess number of deaths observed compared with that expected is also given in table 6 and may be interpreted as the extra number of deaths observed in the study population, from the neoplasms specified, per 100 patients per year. Inspection of table 6 indicates that the excess number of neoplastic deaths among five year survivors of retinoblastoma, non-Hodgkin lymphoma, and Wilms' tumour was consistently less than one extra death per 100 patients per year. The excess among survivors of Hodgkin's disease, tumours of the central nervous system and bone tumours did not exceed five extra deaths per 100 patients per year. The largest excess observed was after acute lym-

Table 4 Deaths from medical conditions related to treatment of the tumour $(n=49)$

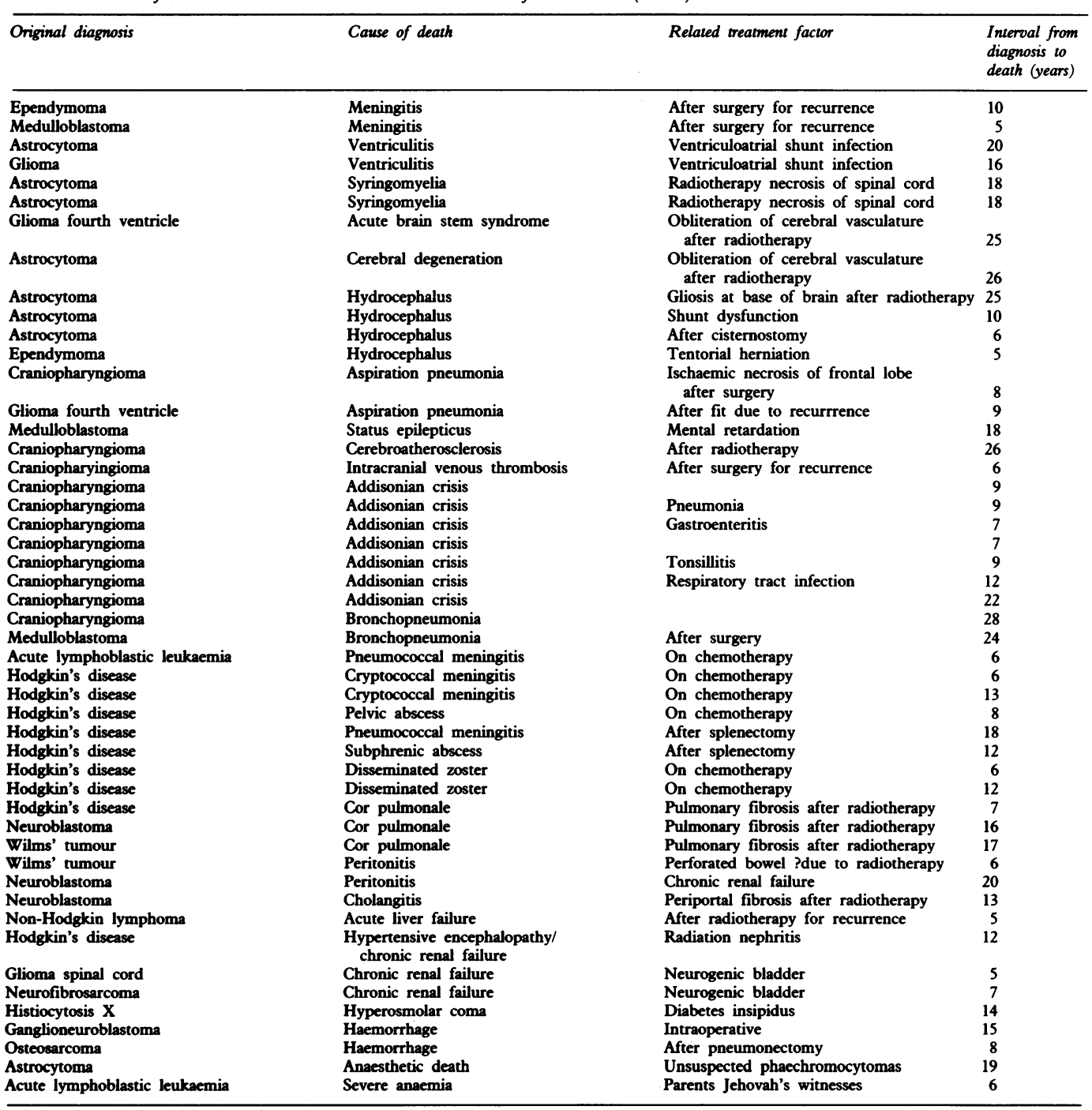


Table 5 Actuarial percentage of five year survivors subsequently dying of recurrent tumour

\begin{tabular}{lcc}
\hline Diagnosis & $\begin{array}{l}\text { No of } 5 \\
\text { year } \\
\text { survivors }\end{array}$ & $\begin{array}{l}\text { \% (SE) of 5 year survivors } \\
\text { dying of recurrent tumour } \\
\text { by 20 years from diagnosis }\end{array}$ \\
\hline Acute lymphoblastic leukaemia & 171 & $47(4)$ \\
Lymphomas: & 538 & $18(2)$ \\
Hodgkin's disease & 328 & $26(3)$ \\
Non-Hodgkin lymphoma & 203 & $6(2)$ \\
Tumours of central nervous & 1257 & $20(1)$ \\
system: & 123 & $26(4)$ \\
Ependymoma & 670 & $15(1)$ \\
Astrocytoma & 165 & $34(4)$ \\
Medulloblastoma & 230 & $6(2)$ \\
Neuroblastoma & & \\
Retinoblastoma: & 267 & $3(1)$ \\
Genetic & 287 & 0 \\
Non-genetic & 365 & $2(1)$ \\
Wilms' tumour & 151 & $15(3)$ \\
Malignant bone tumours: & 73 & $10(4)$ \\
Osteosarcoma & 40 & $30(7)$ \\
Ewing's tumour & 352 & $7(1)$ \\
Soft tissue sarcoma: & 87 & $7(3)$ \\
Rhabdomyosarcoma & 175 & $5(2)$ \\
Fibrosarcoma & & \\
\hline
\end{tabular}

phoblastic leukaemia and exceeded 10 extra deaths per 100 patients per year.

Table 7, again using information from death certificates only, gives the results of comparing the observed and expected number of deaths from all causes other than neoplasm. Threefold the expected number of non-neoplastic deaths were observed. We observed 13-fold the number of deaths expected from infections other than pneumonia and influenza. The excess of deaths assigned to pneumonia and influenza, particulary after central nervous system tumours, needs careful interpretation because of the tendency of many clinicians to record bronchopneumonia as the cause of death in patients with recurrent tumours of the central nervous system, but may also reflect the problem of prolonged impairment of immunity in patients with a history of cancer. Of the eight

Table 6 Comparison of observed and expected deaths from neoplastic causes

\begin{tabular}{|c|c|c|c|c|c|c|}
\hline & \multicolumn{6}{|c|}{ Interval from diagnosis in years } \\
\hline & \multicolumn{3}{|l|}{$5-9$} & \multicolumn{3}{|l|}{$10+$} \\
\hline & Observed $(\mathrm{O})$ & Expected $(E)$ & Excess* & Observed $(O)$ & Expected $(E)$ & Excess* \\
\hline $\begin{array}{l}\text { Acute lymphoblastic leukaemia } \\
\text { Hodgkin's disease } \\
\text { Non-Hodgkin lymphoma } \\
\text { Tumour of central nervous system } \\
\text { Genetic retinoblastoma } \\
\text { Non-genetic retinoblastoma } \\
\text { Wilms' tumour } \\
\text { Malignant bone tumour }\end{array}$ & $\begin{array}{r}71 \\
70 \\
8 \\
141 \\
5 \\
0 \\
8 \\
14\end{array}$ & $\begin{array}{l}0.009 \\
0.011 \\
0.006 \\
0.085 \\
0.000 \\
0.000 \\
0.004 \\
0.005\end{array}$ & $\begin{array}{r}12 \cdot 5 \\
5 \cdot 1 \\
0 \cdot 9 \\
2 \cdot 5 \\
0 \cdot 4 \\
0 \cdot 0 \\
0 \cdot 4 \\
2 \cdot 1\end{array}$ & $\begin{array}{r}7 \\
17 \\
1 \\
89 \\
2 \\
0 \\
2 \\
2\end{array}$ & $\begin{array}{l}0.007 \\
0.035 \\
0.022 \\
0.210 \\
0.000 \\
0.000 \\
0.005 \\
0.007\end{array}$ & $\begin{array}{l}0 \cdot 9 \\
0 \cdot 6 \\
0 \cdot 0 \\
0 \cdot 7 \\
0 \cdot 1 \\
0 \cdot 0 \\
0 \cdot 0 \\
0 \cdot 1\end{array}$ \\
\hline
\end{tabular}

*Excess $=\left\{\frac{(\mathrm{O}-\mathrm{E}) 100}{\text { person years }}\right\}$

Table 7 Comparison of observed and expected deaths from non-neoplastic causes five or more years from diagnosis

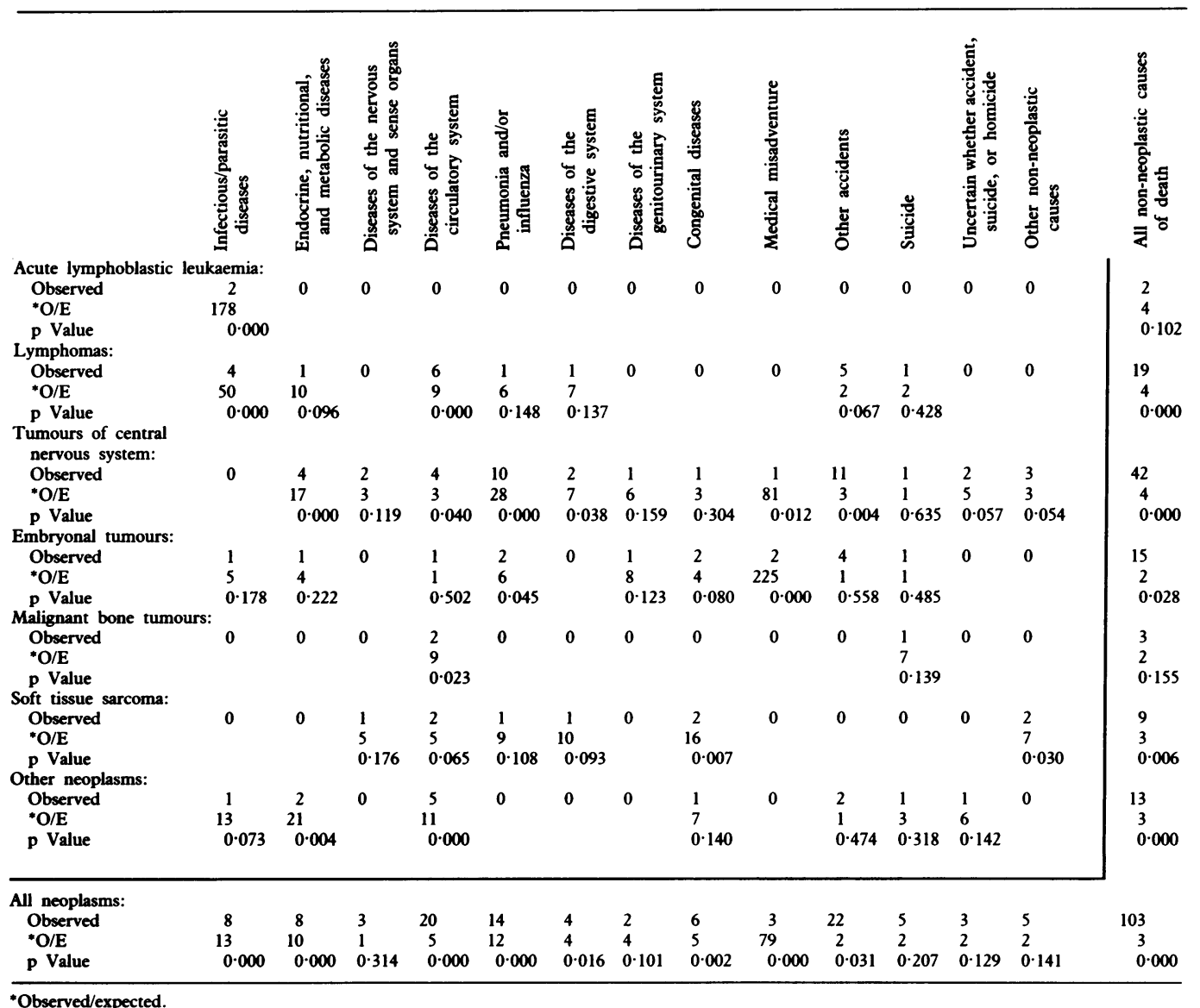

Observed/expected. 
deaths coded to endocrine or metabolic causes, two deaths were due to the metabolic complications of diabetes mellitus, one death was from hyperosmolar coma secondary to diabetes insipidus in a patient with Langerhans cell histiocytosis, and one death was due to cor pulmonale secondary to severe bronchiectasis resulting from recurrent infections in a patient with hypogammaglobulinaemia. In the remaining four cases, the cause of death on the death certificate was inaccurate as inspection of the notes indicated that death was due to recurrent tumour. However, excluding the latter four deaths still leaves an excess (one tailed $p=0.01$ ).

The fivefold excess of cardiovascular deaths were predominantly myocardial infarction or cerebrovascular accidents, which occurred at a younger age than expected for these conditions. There were eight deaths due to myocardial infarction; two patients had diabetes mellitus which may have contributed to the early onset of coronary atheroma. It is of interest that three patients had received radiotherapy to the mediastinum and one to the left infraclavicular region. Seven patients, aged $26-42$ years, died from cerebrovascular accidents, three patients had previously received direct irradiation to some part of the brain. Three of the cerebrovascular accidents occurred in patients who had documented severe hypertension, one resulted from a subarachnoid haemorrhage secondary to a berry aneurysm, two were unexplained and the remaining patient, treated for a craniopharyngioma, was found to have extensive cerebroatherosclerosis at necropsy. Of the remaining cardiovascular deaths, one was due to left ventricular failure in a patient with severe hypertension and chronic renal failure, and one to congestive cardiac failure in a patient with severe kyphoscoliosis. In three cases the certified cause of death from circulatory causes was inaccurate as examination of the patient's records indicated that they had actually died from the effects of recurrent disease and the death certificates in these cases were, therefore, misleading. However, even after excluding these three deaths there was still an excess of cardiovascular deaths (one tailed $p<0.001$ ).

There was fivefold excess of deaths from congenital causes as coded from the death certificate. Of the six deaths thus coded, three were in patients with von Recklinghausen's disease, one of the patients dying from renal failure which was tumour related and two from recurrent tumour. There were two further deaths from renal failure, one in a patient with Wilms' tumour and polycystic kidneys and one in a patient with neuroblastoma and spina bifida who had a neurogenic bladder and hydronephrosis. The final death in this category was due to mechanical failure of an aortic valve prosthesis in a patient with congenital heart disease.

Considering all neoplasms as a single group there was no evidence of an excess of deaths from suicides. The excess of deaths from accidents other than medical misadventure was predominantly due to observing threefold the expected number of accidents after tumours of the central nervous system. A total of 11 patients who had been treated for these tumours died from accidents. Six of these patients (aged 10 to 35 ) died in road traffic accidents, two teenagers died from burns caused by accidental fires and hot water scalds at home, and two patients from complications after falls. The final death was due to manual strangulation, but in what circumstances this occurred is uncertain. Apart from one child with an optic nerve glioma who was visually handicapped we can only speculate that the effect of the tumour or treatment had resulted in some sensory or intellectual impairment that increased the risk of these patients becoming involved in accidents.

\section{Discussion}

Ascertaining the cause of death in a population of children who were diagnosed before 1971 was not easy as some hospitals destroy medical records at a specified number of years after death, and even when records were available, it was sometimes difficult to be completely sure of the actual cause of death. Fortunately, in the present study, we obtained hospital notes or a postmortem examination report for $80 \%$ of the deaths from causes other than recurrent tumour. We were most confident of our assessment where a postmortem examination report was available.

The good long term prospects for five year survivors of childhood non-Hodgkin lymphomas, neuroblastoma, retinoblastoma, Wilm's tumour, and soft tissue sarcoma, treated before 1971 , are confirmed in our study with less than $10 \%$ dying of recurrent tumour during the subsequent 15 years.

For all types of childhood neoplasm the results of our study are similar to those of $\mathrm{Li}$ et al who reported on 2232 five year survivors of a variety of childhood cancers diagnosed before $1970 .^{7}$ Our findings are also similar to those of Taylor and Potish who reported on 37 deaths occurring among 189 five year survivors of childhood cancer treated with megavoltage radiotherapy between 1953 and 1975.8

Our study indicates that in children with central nervous system tumours, deaths from recurrent tumour were still occurring more than 20 years from diagnosis. Many central nervous system tumours, particularly low grade astrocytomas and craniopharyngiomas, are relatively slow growing and so deaths may occur many years after the initial diagnosis. It is also recognised that both Hodgkin's disease and Ewing's tumour are indolent tumours and multiple relapses responding to further treatment can occur over a period of several years before eventual death from disease occurs.

The high frequency of deaths from recurrent disease after acute lymphoblastic leukaemia is partly explained by a large number of central nervous system relapses occurring during an era when children were not routinely given central nervous system irradiation and intrathecal methotrexate to reduce the risk of meningeal leukaemia. Central nervous system leukaemia may take a very indolent course, being partially controlled for long periods, and it may be several years before either a subsequent bone marrow relapse occurs or the child develops 
resistant central nervous system disease. In addition, some children with meningeal leukaemia may develop an encephalopathy from the combination of repeated cranial irradiation and intrathecal methotrexate and this may not become manifest until several years after treatment.

In our study second primary tumours as a cause of death were relatively more commonly seen in patients with genetic retinoblastoma and Wilms' tumour. We have reported on the pattern and incidence of second primary tumours among survivors of childhood cancer elsewhere. ${ }^{910}$

Of the 49 deaths from causes related to treatment, at least 21 occurred in children undergoing treatment for recurrent disease and these deaths were probably unavoidable due to the intensity of treatment required in the presence of resistant disease. However, it is possible that a number of the remaining 28 deaths might have been preventable. The main cause of potentially avoidable death was from endocrine failure $(n=$ 7) in children with craniopharyngioma and panhypopituitarism who presented with addisonian crises in periods of stress related to infection. It is possible that the need for high doses of intravenous corticosteroids, which might have been life saving, was not recognised in these cases.

The other major cause of death related to primary treatment was from problems secondary to post radiation fibrosis. Five children with astrocytoma developed radiation related central nervous system degeneration, three children developed pulmonary fibrosis after whole lung irradiation and three children developed fibrosis of abdominal organs after abdominal irradiation. It is very difficult to know whether these problems could have been avoided by a more judicious approach to radiotherapy. However, in some cases radiation was given for recurrent disease and therefore the effect of radiation was probably unavoidable.

The only previous study of potentially avoidable deaths after diagnosis of childhood cancer was a Finnish study of mortality among 100 children diagnosed with acute lymphoblastic leukaemia, between 1975 and 1981. ${ }^{11}$ This study identified five deaths from infections occurring during induction or primary remission that might have been avoided.

Of the $\mathbf{4 4}$ late deaths in our study classified as being unrelated to the primary cancer or its treatment the most frequently occurring cause of death was due to cardiovascular disease $(n=$ 20), including eight deaths due to coronary atherosclerosis and seven due to cerebrovascular accidents. Four of the eight deaths occurred in patients who had received mediastinal or chest irradiation and it is possible that the irradiation may have contributed to the early development of coronary atheroma. All the patients dying from coronary artery disease were relatively young at the time of death (age range 23-45 years). There were eight deaths from infection in patients who were off treatment and in remission from their cancer. This highlights the point that children may remain relatively immunocompromised for many years after treatment.
A previous report of an excess of cerebrovascular accidents in children diagnosed with cancer identified 26 such cases among 700 children. ${ }^{12}$ The average follow up interval was short, however, and all of the deaths occurred a median time of five months after diagnosis. Results from this study taken together with those from our study indicate that survivors of childhood cancer are at an increased risk of cardiovascular death immediately after diagnosis and remain so beyond five years from diagnosis, although the aetiology of these early and late deaths are almost certainly different.

In conclusion we observed a five times expected excess of deaths due to cardiovascular causes, with deaths from myocardial infarction and cerebrovascular accidents being most frequent. The long term effects of radiation on the coronary vasculature of children have not been established but there is obvious concern that radiotherapy may predispose to the early development of coronary atheroma. The excess number of cerebrovascular accidents did not appear to be due to a direct effect of radiotherapy on the cerebral vasculature.

Among the deaths classified as being related to treatment we identified two groups of potentially avoidable deaths. One group consisted of children with craniopharyngioma and secondary hypothalamic-pituitary dysfunction, after surgery and radiotherapy, who died from adrenal failure during periods of stress. The other group consisted of children who received inappropriate doses of radiation and died from problems related to radiotherapy fibrosis.

We emphasise that our investigation relates to patients treated for childhood cancer before 1971 and who were treated predominantly by surgery and radiotherapy. The pattern of mortality after more recent treatment regimens, in which chemotherapy has been used extensively and radiotherapeutic techniques have been refined, are likely to be different. With the knowledge of the potential long term effects of treatment, it is hoped that future protocols can be planned to reduce the risk of late treatment related deaths. The information gained from the study of late deaths should also be of value in helping give appropriate advice and monitor the health of potentially 'at risk' groups of patients.

We thank Michael Potok, Elizabeth Mowat, David Winter, and Joanne Sturdy for their help with this work. Particular thanks to members of the Long-term Follow-up Study Working Party (Dr GJ Draper, Professor DG Harnden, Professor JS Malpas, Dr JR Mann, Professor HB Marsden, Dr PH Morris Jones, and Dr D Spooner) for their advice and support.

Spooner) for their advice and support. The Long-term Follow-up Study is supported by the Cancer Research Campaign and the Leukaemia Research Fund. The Childhood Cancer Research Group is supported by the Department of Health and the Scottish Home and Health Department. The work would be impossible without the help of the Office of Population Censuses and Surveys (particularly the National Health Service Central Registers), the Information Services Division of the Common Services Agency of the Scottish Health Ser-
vice, the Registrar General for Scotland, and the regional cancer vice, the Registries.
reger

1 Hawkins MM. Long term survival and cure after childhood cancer. Arch Dis Child 1989;64:798-807.

2 World Health Organisation. Manual of the international statistical classification of diseases, injuries, and causes of death. 6th Revision. Geneva: WHO, 1948.

3 World Health Organisation. Manual of the international statistical classification of diseases, injuries, and causes of death. 7 th Revision. Geneva: WHO, 1955 
4 World Health Organisation. Manual of the international statistical classification of diseases, injuries, and causes of death. 8th Revision. Geneva: WHO, 1965.

5 World Health Organisation. Manual of the international statistical classification of diseases, injuries, and causes of death. 9th tical classification of diseases, injuries,

6 Peto R, Pike MC, Armitage P, et al. Design and analysis of randomized clinical trials requiring prolonged observation of each patient. Br $\mathcal{F}$ Cancer 1977;35:1-39.

$7 \mathrm{Li} \mathrm{FP,} \mathrm{Myers} \mathrm{MH,} \mathrm{Heise} \mathrm{HW,} \mathrm{Jaffe} \mathrm{N.} \mathrm{The} \mathrm{course} \mathrm{of} \mathrm{five-}$ year survivors of cancer in childhood cancer. Pediatrics 1978;93:185-7.

8 Taylor DD, Potish RA. Late deaths following radiotherapy for paediatric tumours. Am $\mathcal{f}$ Clin Oncol 1985;8:472-6.

\section{Forty years ago}

The 1950 volume of the Archives of Disease in Childhood contained papers by two paediatric pathologists. At the time of publication Ian Cathie was haematologist to the Hospital for Sick Children, Great Ormond Street, and Albert Claireaux was to become its morbid anatomist some years later.

\section{Congenital hypoplastic anaemia}

Congenital hypoplastic anaemia is characterised by the onset in the first few weeks of life of a severe normocytic, normochromic anaemia. The peripheral blood shows normal white cells and platelets but no reticulocyte response to the anaemia. The marrow contains normal myeloid precursors and megakaryocytes but grossly reduced normoblasts.

Cathie described five patients with these findings and noted a characteristic facies common to all five-tow coloured hair, snub nose, thick upper lip, wide set eyes, and an intelligent expression. ${ }^{1}$ The only treatment available was repeated blood transfusion and Cathie commented on the need to resort to tranfusing packed cells into the external jugular veins when all the peripheral limb veins had been tied off after several years of transfusions by the 'cut down' technique. (Elderly readers of this journal who were house physicians at Great Ormond Street in the late 1940s will remember these five patients only too well.)

An interesting feature of this paper was Cathie's discussion of the nomenclature of the disease. He considered 'congenital hypoplastic anaemia', the term which had been used by Blackfan and Diamond in the United States, to be inaccurate and suggested 'erythrogenesis imperfecta' which better described what he felt was a failure of red cell maturation. This term was used in the UK for some time but others, such as 'Blackfan-Diamond syndrome' and 'pure red cell aplasia' became more popular.

Haemolytic disease of the newborn Claireaux reported a study of 157 cases of
9 Kingston JE, Hawkins MM, Draper GJ, Marsden HB, Kinnier Wilson LM. Patterns of multiple primary tumours in nier Wison LM. Patrerns of multiple primary tumours in 1987;56:331-8.

10 Hawkins MM, Draper GJ, Kingston JE. Incidence of second primary tumours among childhood cancer survivors. $\mathrm{Br} \mathcal{F}$ primary tumours among

11 Saarinen UM, Rapola J. Inevitable and avoidable deaths in childhood ALL. Acta Paediatr Scand 1986;75:316-20.

12 Packer RJ, Rorke LB, Lange BJ, Siegel KR, Evans AE. Cerebrovascular accidents in children with cancer. Pediatrics 1985;2:194-201. haemolytic disease of the newborn collected between 1938 and 1947 in Edinburgh. ${ }^{2}$

There were 36 cases of hydrops fetalis, of whom 31 were stillborn and five died within hours of birth. In a further 110 babies there was an early onset of severe jaundice (icterus gravis neonatorum). The overall mortality in the jaundiced group was $70 \%$, with the highest mortality in those whose jaundice developed at birth or within 24 hours. Eleven babies had haemolytic anaemia without severe jaundice and of these three died.

Late in 1947 the direct Coombs test became available and was carried out on all babies from then on. Serum bilirubin concentrations were measured in most cases of severe jaundice and ranged from 2 to $20 \mathrm{mg} / 100 \mathrm{ml}$ ( 34 to $340 \mu \mathrm{mol}$ 1). Babies with concentrations over $7 \mathrm{mg} / 100 \mathrm{ml}$ (119 $\mu \mathrm{mol} / \mathrm{l})$ at birth seldom recovered.

Treatment was simple transfusion of $R h$ negative blood in quantities of $15 \mathrm{ml} /$ pound body weight, repeated as necessary. At first the anterior fontanelle was used, then the saphenous vein at the ankle, and only in the later cases was transfusion given by the umbilical vein. Of 35 babies treated by simple transfusion 17 died. The author reported that a new transfusion technique (exchange transfusion) was being tried at the time of writing but that the early results were less satisfactory than had been anticipated.

Kernicterus did not develop in any baby before the age of 18 hours but was present in 37 (34\%) of the cases of severe jaundice. The serum bilirubin concentrations in babies with kernicterus ranged from 10 to $20 \mathrm{mg} / 100 \mathrm{ml}$ (170 to $340 \mu \mathrm{mol} / \mathrm{l}$ ). All but two of the babies with kernicterus died: 33 within two weeks of birth. Four babies survived beyond the age of 2 weeks: two died in infancy and two survived to develop cerebral palsy.

\footnotetext{
Cathie I. Erythrogenesis imperfecta. Arch Dis Child

1950;25:313-24.
Claireaux A. Haemolytic disease of the newborn. Part 1. A clinico-pathological study of 157 cases. Part 2. Nuclear
2. Nart clinico-pathological study of 157 cases. Part 2. Nuclear
jaundice (kernicterus). Arch Dis Child 1950;25:61-80.
}

ADM JACKSON 